\title{
Study of Breast Tissues Dielectric Properties in UWB Range for Microwave Breast Cancer Imaging
}

\author{
M.H. Bah, J.S. Hong, D.A. Jamro \\ School of Physical Electronics \\ University of Electronic Science and Technology of China \\ Chengdu, China
}

\begin{abstract}
In this manuscript, we study about dielectric properties of major tissues in the breast within the UWB allocated frequency band. Some tissues mimicking phantoms have been designed and measured using slub-line tool system. The results obtained show good representation for both normal and malignant breast tissues. The tissues phantoms are made from mixture of common materials which are low cost, non toxic and widely available in our daily life.
\end{abstract}

Keywords-breast tissues phantoms; breast cancer; dielectric characteristics; microwave imaging; UWB frequency range

\section{INTRODUCTION}

The rapid development of sectors using microwaves and radio frequencies brought huge changes in our daily life, particular in telecommunications and medical applications. The daily use of radio and microwave frequencies attracted the attention of many research groups and medical institutions in order to evaluate its effect when interacting with human body. This interaction affects the some parameters of the tissues in human body at macroscopic and even microscopic levels. [1] Thus appears the need of investigating in the electrical properties of biological tissues based on the dielectric properties at micro and macroscopic stages. To facilitate this investigation with a safety manner, many studies have been carried out on biological tissues mimicking phantoms representing different parts of the body for different range of frequencies. [2]. For example tissues mimicking phantoms for different parts of the body such as brain and breast tissues have been reported in $[3,4,5]$ for a wide applicability range (from ultrasound to microwave frequencies). However, breast mimicking samples used in microwave imaging are mostly liquid and sometimes formed by chemical materials which are somehow risky during experiment.

According to Schwan, the electromagnetic waves dispersion in biological tissues can be classified into three different relaxation ranges: $\alpha, \beta$, and $\gamma$ mainly related to the various properties of the tissues [6]. Alpha $(\alpha)$ is from 0.1 $\mathrm{KHz}$ to $100 \mathrm{kHz}$ and depends on outer cell membranes impedance. The $\beta$ dispersion is from $1 \mathrm{MHz}$ to $20 \mathrm{GHz}$ and is due to the presence of bound water in some membrane cellules. In between $\alpha$ and $\beta$, there is another transition region known as sigma $\delta$ which ranges from a few hundred $\mathrm{MHz}$ to several GHz. [7]. And then finally gamma $(\gamma)$ occurs around $20 \mathrm{GHz}$. It is mainly related to the water dispersion in the tissues.
With the increase of breast cancer mortality in the recent decades, many methods using breast phantoms have been studied and experimented in order to estimate the real breast tissues properties $[2,4,5,8,9]$. The use of oil in gelatin has been implemented by Lazebnik et al in [4]. This method consists of mixing these two materials and adding surfactant liquids. It has been also utilized by Madsen et al [10] in the field of ultrasound for tissues mimicking.

In previous studies, the permittivity of malignant tissues (tumor) was found 10-20\% higher than the healthy tissues [4]. Due to the variability of the amount of water in human body, the tissues can be classified into three categories: high water content tissues simulating the malignant (tumor) tissues; the intermediate water content tissues representing the skin and other transitional tissues and then finally, the low water content tissues which simulate the normal tissues.

\section{BREAST TISSUES PHANTOMS MODELLING}

In our experiment, we make use of some common materials having different electrical properties and mix them together in different ratios to mimic the breast tissues within the industrial science and medical (ISM) frequency range generally taking from 1 to $20 \mathrm{GHz}$. In this work, we are interested particularly in the UWB range 3.1-10.6 GHz. Some half spherical plastic bowls with a diameter of $12 \mathrm{~cm}$ and radius of $6 \mathrm{~cm}$ are used as container. The main materials used here are water, soy bean oil, peanut, corn flour, wheat flour and Vaseline cream. Figure $2 \mathrm{~b}$ shows one of the samples before the mixture. For this dielectric characteristics measurement, a slub-line directly connected to a VNA (Vector Network Analyzer) was employed. Before performing the measurement, the VNA was calibrated from 3.1 to $10.6 \mathrm{GHz}$. In this experiment, our aim is to achieve more accurate dielectric properties (relatively close that of the human breast tissues) without the use of any chemical materials. For that, some samples will be made and experimental measurement will be carried out. Looking to the complexity of human body tissues and referring to [11], we categorize breast tissues into three different groups due to water content in it. So we will have the high water content tissues (HWCT) representing the malignant tumor, the intermediate water content tissues (IWCT) for the skin and some transitional tissues; and then the low water content tissues (LWCT) for the normal tissues. Note that there are many others tissues in the human body which have not being covered in this study. It is out of scope to this present work. During the measurement, we will be interested to the relative permittivity ${ }^{\varepsilon_{r}}$ which is the capability of a 
material to stock more energy in it, the loss factor $\varepsilon_{r}$ that represents the dispersion characteristic due to an external electric field, and then the conductivity $\sigma$ of the different phantoms. However due to the complexity of the human tissues, it varies from one person to another $[2,9,12]$. The complex permittivity can be express as giving in this following equation (1).

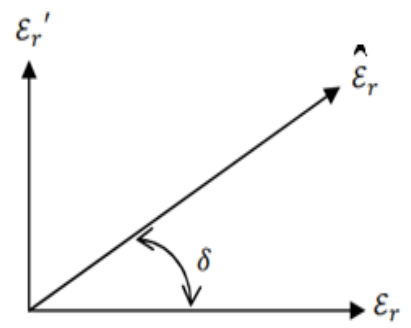

FIGURE I. COMPLEX PERMITTIVITY VECTOR DIAGRAM

$$
\begin{aligned}
\hat{\varepsilon}=\varepsilon_{o}\left(\varepsilon_{r}-j \varepsilon_{r}^{\prime}\right) & =\varepsilon_{o}\left(\varepsilon_{r}-\frac{j \sigma}{\omega \varepsilon_{o}}\right)=\varepsilon_{o} \varepsilon_{r}(1-\tan \delta) \\
\varepsilon_{r}^{\prime} & =\frac{\sigma}{\omega \varepsilon_{o}} ; \sigma=2 \pi f_{o} \varepsilon_{o} \varepsilon_{r}^{\prime}
\end{aligned}
$$

In these equations, $\varepsilon_{o}=8.854 \times 10^{-12}(F / m)$ is the permittivity in free space, ${ }^{\varepsilon_{r}}$ is the relative permittivity of the material, $f_{o}$ is operating frequency point, $\sigma(S / \mathrm{m})$ is the conductivity and $\tan \delta=\varepsilon_{r} / \varepsilon_{r}$ is the loss tangent. "When complex permittivity is drawn as a simple vector diagram (figure 1), the real and imaginary components are $90^{\circ}$ out of phase and then the vector sum forms an angle $\delta_{\text {with the real }}$ axis" (Kim-Mey Chew et al, 2012) [12]. In (1) the conductivity is deduced and plotted in the following section.

\section{TISSUE PHANTOMS SAMPLES CONFIGURATION}

Here we present the configurations of the breast major tissues samples referring to the three different tissue groups such as normal breast tissues, skin and malignant (tumor) tissues.

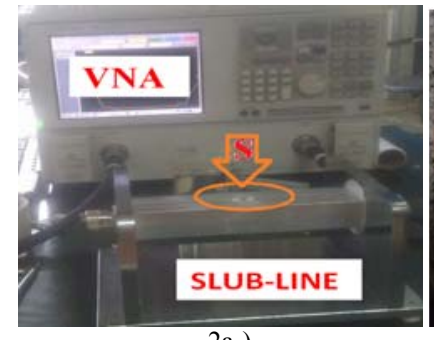

2a-)

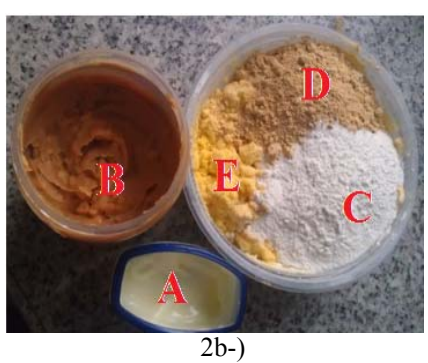

2b-)
FIGURE II. 2A-) VNA \& SLUB-LINE IN THE LABORATORY: "S" STANDS FOR SAMPLE AND THE ARROW INDICATES THE OPENING WHERE SAMPLES ARE LOADED DURING EXPERIMENT. 2B-) SOME MATERIALS USED IN THE EXPERIMENT: (A) REPRESENTS VASELINE CREAM, (B) IS PEANUT BUTTER, (C) IS WHEAT FLOUR, (D) IS GRILLED BEAN FLOUR AND (E) IS CORN FLOUR.
For normal breast tissues: (samples 1 \& 2): 1.) Water mixed with Corn flour in a ratio 1:2 is heated for 20 minutes then we added soy bean oil and petroleum jelly pre-mixed then all mixed together and carefully stirred till it makes a jelly like form. This jelly form was considered as normal breast tissues. 2.) A solution resulting from mixing bean oil, wheat flour and peanut butter is added to Vaseline cream in a ratio of $1: 1$.

For the skin: (sample 3): Some Vaseline cream solution and mineral water were carefully added in a ratio $4: 1$ and stirred to uniform the solution.

And then finally for tumor: (sample 4): Vaseline cream and wheat flour were slowly mixed in $2: 1$, after that a ratio of $1: 1$ oil and corn flour were mixed and then the two preview samples were put together into one experimental bottle in which we added some water about $80 \mathrm{ml}$. To control the dielectric constant of this sample due to the high water content, a temperature of about $90 \mathrm{oc}$ was applied to the solution whereas a measurement is carried out every 5 minutes heat.

\section{RESULTS}

This section shows up the results obtained through our experiment. We have been able to achieve a relative permittivity around 10 for the normal tissues due to the low water content in it; and this is close to the real breast tissues as investigated in $[2,13]$. Two different samples (NBT_1 \& NBT 2) are experimented mimicking the normal tissues and plotted in figure 3 . For the skin, a relative permittivity ranging from 30 to 36 is obtained and plotted in figure 3 . This result appears to be very good compared to $[2,13]$. It is high at low frequency and more stabilize towards higher frequency. And finally, due to the high water content, a high dielectric constant is obtained as expected. This is considered as malignant tissues (tumors); see figure 3. Its relative permittivity varies from 40 to 56 and this is very important during the tumor detection. For example, in active microwave breast cancer detection system, the tissues (or cells) having more water in it reflect more strongly the electromagnetic energy transmitted to that particular area. This can facilitate the tumor localization and detection without the need of any preliminary surgery. The loss factor explaining about the energy dissipation in the material is directly proportional to the electric conductivity and inversely proportional to the operating frequency through angular frequency ( $\left.\omega=2 \pi f_{0}\right)$. For better comprehension, the measured result is also plotted in figure 4 whereas the loss factor for the tumor is a little bit higher than expected and this is due to some errors occurring during the experiment.

In our experiment, we observe that the conductivity of the samples depends on loss factor and the operating frequency. It increases with the increase of loss factor and the frequency as depicted in figure 5 . We can tell from the deduced conductivity in equation (2) that it is directly proportional to the operating frequency point. So that it increases with the increase of frequency and / or loss factor and decreases otherwise. 


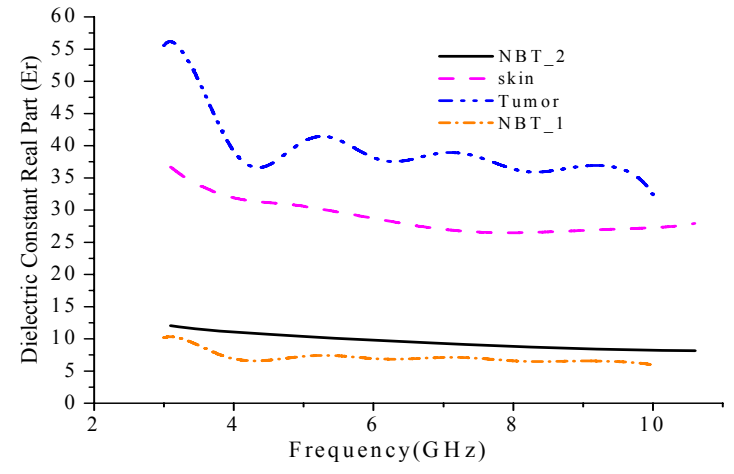

FIGURE III. MEASURED RELATIVE PERMITTIVITY OF DIFFERENT BREAST TISSUES: NBT 1 \& NBT 2 STAND FOR NORMAL BREAST TISSUES.

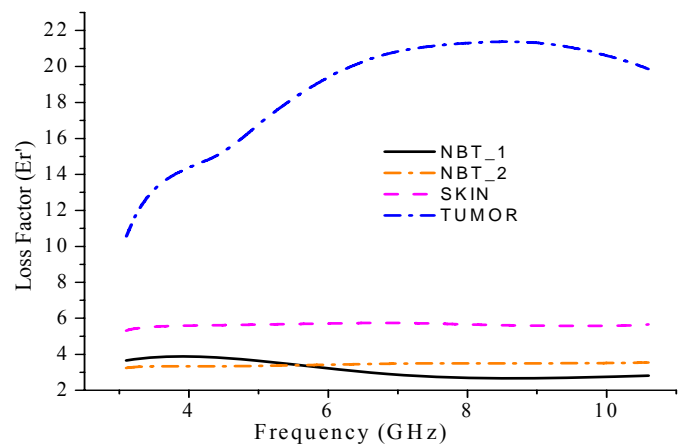

FIGURE IV. MEASURED LOSS FACTOR OF DIFFERENT BREAST TISSUES: NBT_1 \& NBT_2 STAND FOR NORMAL BREAST TISSUES.

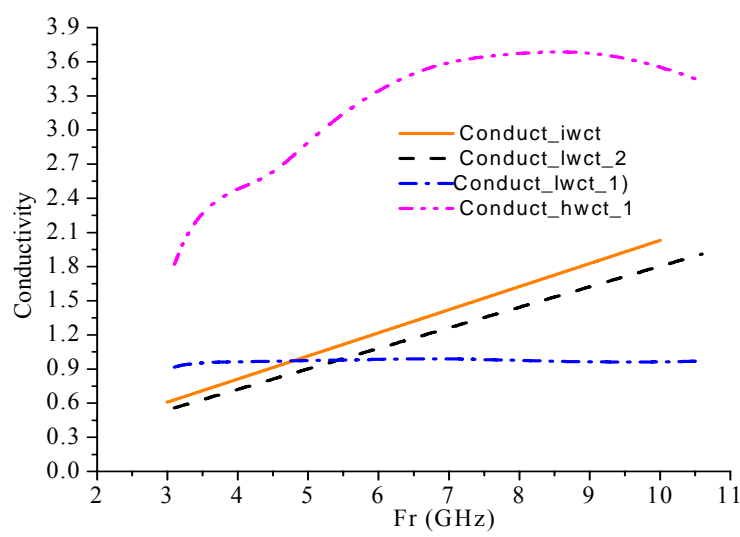

FIGURE V. MEASURED CONDUCTIVITY OF THE TISSUES GROUPS.

\section{$\mathrm{V} \quad$ CONCLUSIONS}

In this research, some breast tissues mimicking phantoms are considered and studied for microwave breast cancer imaging. Dielectric constants mimicking normal tissues, skin and tumor relatively close to real breast tissues have been achieved $[2,9,13]$. It is also very challenging to achieve good result by mixing different materials having different dielectric characteristics at relatively high frequency. During this experiment all the materials used are non toxic, very safe through physical contact even through inhalation.
Through this work, we have found that the slub-line system is a good tool in the measurement of minced materials. It can also measure some liquid content materials; however the accuracy is very limited when the amount of liquid is much greater than the other constituent materials. For further improvement in the accuracy of the result, it would be easier to use a Microstrip probe line system which can be employed for both solid and liquid materials measurement. We look forward doing experiment using Microstrip probe line system and do comparison between the results obtained from the two systems.

\section{REFERENCE}

[1] K R Foster, J L Schepps, R D Stoy, H P Schwan, "Dielectric properties of brain tissue between 0.01 and $10 \mathrm{GHz}$ ", Physic Medicine Biology 1979 Nov;24(6):1177-87.

[2] E.C. Fear, X. Li, S.C. Hagness, and M.A. Stuchly, "Confocal microwave imaging for breast cancer detection: localization of tumors in three dimensions," IEEE Trans. Biomed. Eng., vol. 49, (no. 8), pp. 812-22, Aug 2002.

[3] D. Andreuccetti, M. Bini, A. Ignesti, R. Olmi, N. Rubino, and R. Vanni, "Use of polyacrylamide as a tissue-equivalent material in the microwave range," IEEE Transition on Biomedical Engineering, volume 35, no. 4, pp. 275-277, Apr. 1988.

[4] M. Lazebnik, E.L. Madsen, G.R. Frank, and S.C. Hagness, "Tissuemimicking phantom materials for narrowband and ultra-wideband microwave applications," Physic. Medicine Biology, volume 50, pp. 4245-4258, 2005.

[5] J. Croteau, J. Sill, T. Williams, and E. Fear, "Phantoms for testing radarbased microwave breast imaging," 13th Int. Sym. On antenna and App. Elect (ANTEM), Canada, Feb. 2009.

[6] Schwan, H. P. "Electrical properties of tissue and cell suspensions", Advance Biology Medicine Physic Volume 5.

[7] E.H. Grand, S.E. Keefe, and S. Takashima, "The dielectric behavior of aqueous solutions of bovine serum albumin from radio wave to microwave frequencies," J. Phys. Chem., Vol. 72, pp. 4373-4380, 1968.

[8] Nadine Joachimowicz, N.; Conessa C.; Henriksson, T.; Duchêne, B. "Breast Phantoms for Microwave Imaging", IEEE Antennas and Wireless Propagation Letters, vol. 13, Page(s): 1333 - 1336, 2014.

[9] Natalia K. Nikolova, "Microwave Imaging for Breast Cancer". Microwave Magazine, IEEE. Volume 12. Pages 78-94. Date: 12/2011.

[10] Madsen, E. L., J. A. Zagzebski, and G. R. Frank, "Oil-in-gelatin dispersions for use as ultrasonically tissue-mimicking materials, "Ultrasound in Medicine and Biology, Vol. 8, 277-287, 1982.

[11] Trehan, A.; Nikolova, N.K.; Noseworthy, M.D. "Physical Phantoms for Microwave Imaging of the Breast”, Biomedical Wireless Technologies, IEEE Networks, and Sensing Systems (BioWireleSS), Page(s): $73-76$ 2012.

[12] Kim-Mey Chew ; Sudirman, R. ;Seman, N. ; Ching-Yee Yong, "Human Brain Phantom Modeling Based on Relative Permittivity Dielectric Properties", Biomedical Engineering and Biotechnology (iCBEB), Page(s): 817-820, 2012.

[13] Sara M. Salvador and Giuseppe Vecchi, "Experimental Tests of Microwave Breast Cancer Detection on Phantoms", IEEE Transactions On Antennas and Propagation, Vol. 57, Page(s): 1705 - 1712, June 2009. 